\title{
Rostos e máscaras no discurso políti- co: efeitos de verdade
}

Rudney Soares de SOUZA

\section{Considerações iniciais}

Este capítulo está fundamentado nos princípios teórico-metodológicos da Análise do Discurso (AD), de modo particular nas perspectivas enunciativo-discursivas de Maingueneau (2008) e Charaudeau $(2008,2012)$. Considerando o caráter interdisciplinar da $\mathrm{AD}$, tratamos também da reflexão histórica sobre a noção de política apresentada por Bobbio (1998). Os dados concretizados neste capítulo resultam de uma pesquisa de doutorado já concluída, em que propusemos como tema o estudo da cenografia, da força do ethos discursivo, do carisma e do poder da mídia em campanhas político-eleitorais midiatizadas para presidente do Brasil em 2014. 
O objetivo geral deste capítulo é examinar os efeitos de verdade em discursos proferidos por Dilma Rousseff e Aécio Neves, no HGPE (Horário Gratuito de Propaganda Eleitoral). Os objetivos específicos são: a) identificar estratégias discursivas que visam a dissociar o sujeito portador do rosto, da voz e do corpo, do enunciador que se diz no discurso e que busca, por meio de máscaras, a adesão do co-enunciador; b) depreender a negociação de efeitos de sentido realizada entre os coenunciadores da cena política.

O capítulo está organizado em três seções. Na primeira, partimos da reflexão sobre o papel da interdisciplinaridade e do alcance inovador da $\mathrm{AD}$, particularmente no que concerne à importância das condições sócio-históricas de produção dos discursos político-eleitorais em cena na sociedade brasileira, para tratar de cenografia, ethos discursivo e carisma. Na segunda, constituímos a amostra e analisamos recortes para verificar relações discursivas que autorizam o enunciador a articular sua imagem pessoal com seu conhecimento de política e sua competência linguístico-discursiva, incorporando discursividades que o projetam no discurso do HGPE. Na terceira seção, considerações finais, apresentamos os resultados que mostraram que, no HGPE, discursos político-eleitorais midiatizados buscam sacralizar o enunciador como carismático, por meio de efeitos de verdade que o tornam, em comparação com seus adversários, mais honesto, mais crível, mais realizador e mais humano. 


\section{A AD e as condições sócio-históricas de produção do discurso político}

É fato que a $\mathrm{AD}$ nos permite produzir efeitos de sentido a partir de uma relação que se estabelece entre o discurso e sua exterioridade, retomando aquilo que já foi dito. Maingueneau (2007) afirma que, quando se fala em $\mathrm{AD}$, não é possível mais ignorar que ela se aplica a trabalhos de inspirações muito diferentes em todo o mundo, pois ela permanece extremamente variável. Segundo o autor,

[...] na era do e-mail e da mobilidade dos pesquisadores, os recortes geográficos e intelectuais tradicionais devem transigir com redes de afinidades científicas que desconhecem fronteiras e que modificam profundamente as linhas de partilha epistemológica. Em análise do discurso, como em outros domínios, a transformação dos modos de comunicação modificou em profundidade as condições de exercício da pesquisa (MAINGUENEAU, 2007, p. 17).

Como se pode ver, a $\mathrm{AD}$ não existe para preencher, simplesmente, um espaço vago na linguística do sistema, como se a uma linguística da "língua" acrescentássemos uma linguística da fala. Maingueneau (2007) assevera que a AD parte da noção de que as disciplinas são complementares e atendem ao propósito de analisar um dado discurso, uma vez que este não é estanque, mas materializa diferentes posicionamentos e condições de produção. 
Com efeito, a $\mathrm{AD}$, por ser interdisciplinar, permite a interface com a Política, uma vez que dispositivos teórico-metodológicos de diferentes ciências humanas e sociais, tais como a Linguística, a Sociologia, a Antropologia, são mobilizados. Para nós, o discurso do sujeito político está circunscrito às condições de sua produção que são marcadas por aspectos sociais, históricos e linguageiros, marcas que poderão ser acessadas na memória discursiva do co-enunciador e, se legitimadas forem, contribuirão para depreensão de efeitos de sentido. Charaudeau \& Maingueneau (2016, p. 114115), definem condições sócio-históricas de produção do discurso como

[...] o que condiciona o discurso, ou seja, trata-se de uma noção que separa enunciado considerado do ponto de vista da pragmática do enunciado considerado do ponto de vista da análise do discurso. As condições de produção desempenham um papel essencial na construção dos corpora, que comportam necessariamente vários textos reunidos em função das hipóteses do analista sobre suas condições de produção consideradas estáveis.

Nesse sentido, tomamos condições sócio-históricas de produção como categoria essencial para a constituição e análise do corpus, uma vez que aspectos sócio-históricos não só situam o tempo e o lugar do discurso, mas também mostram os papéis sociais dos coenunciadores (EU - TU). É o que ilustramos (SOUZA, 2018, p. 28) no esquema a seguir: 


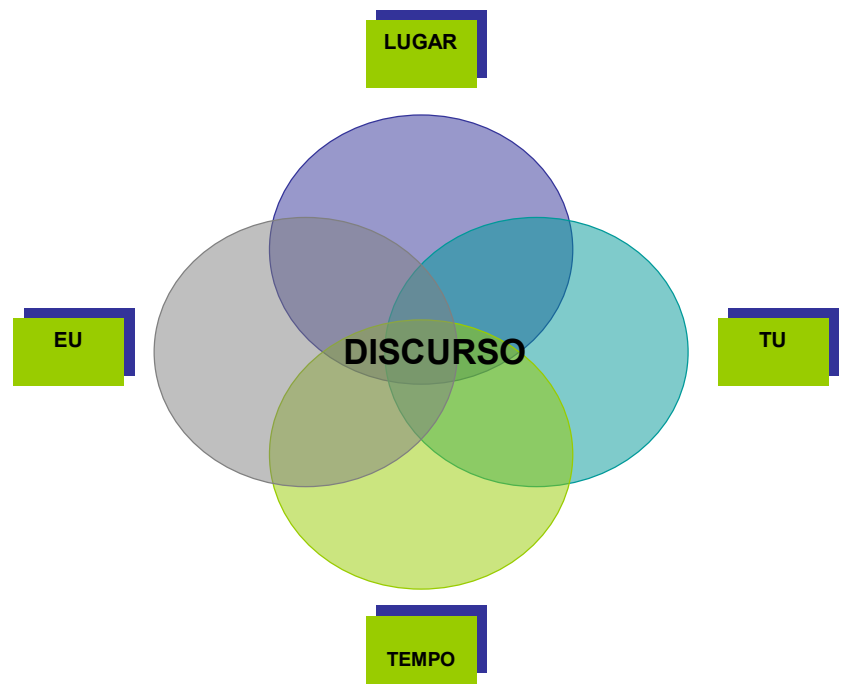

Esquema 1. Condições sócio-históricas de produção do discurso

$\mathrm{A} \mathrm{AD}$, na atualidade, apreende o discurso como intrincação de um texto e um lugar social, o que torna seu objeto aquilo que une, por meio de um dispositivo de enunciação específico, a organização textual e a situação de comunicação. Segundo Maingueneau,

[...] esse dispositivo pertence, simultaneamente, ao verbal e ao institucional: pensar os lugares independentemente das palavras que eles autorizam, ou pensar as palavras independentemente dos lugares com os quais elas estão implicadas significaria permanecer aquém das exigências que fundam a análise do discurso (MAINGUENEAU, 2007, p. 18). 
Para a AD, é na relação da linguagem com o social que o sujeito tem um enunciador constituído totalmente distinto do sujeito empírico. Nas palavras de Nascimento (2013, p. 14),

[...] a AD postula o discurso como uma construção linguística em suas condições de produção, integrando, por conseguinte, a história e o sujeito, categorias imprescindíveis de apreensão a quem se candidata a discutir relações entre textualidade e discursividade.

Desse modo, faz-se necessário recorrer à materialidade linguística e relacioná-la às condições sócio-históricas de produção, no momento de produção dos efeitos de sentido do discurso, quando as categorias carisma e ethos discursivo são desveladas no discurso do enunciador, que assume, no dito, uma imagem de si estereotipada e/ou idealizada e que é capaz de projetar um carisma pronto para mobilizar o co-enunciador para aderir ao discurso e incorporar este aos posicionamentos daquele.

Nas eleições para presidente do Brasil, a partir dos anos 1980, os líderes políticos passaram a agregar identidades coletivas que podem ser identificadas pelo eleitor, independentemente da filiação partidária do candidato, como liderança carismática, ou seja, como candidato político em que se deve votar. A relação dos candidatos com os eleitores passou a ser configurada via mídia, principalmente pela televisão.

\section{Discurso político midiatizado}

Segundo Bobbio, embora apresentado sob perspectivas diferenciadas, etimologicamente, o termo "política" é 
derivado do adjetivo originado de pólis (politikós), que significa tudo o que se refere à cidade e, consequentemente, o que é urbano, civil, público, e até mesmo sociável e social, o termo Política se expandiu graças à influência da grande obra de Aristóteles, intitulada Política, que deve ser considerada como o primeiro tratado sobre a natureza, funções e divisão do Estado, e sobre as várias formas de Governo, com a significação mais comum de arte ou ciência do Governo, isto é, de reflexão, não importa se com intenções meramente descritivas ou também normativas, dois aspectos dificilmente discrimináveis, sobre as coisas da cidade (BOBBIO, 1998, p. 954).

Desse modo, considerando a importância da política na vida em sociedade, sobretudo, quanto à divisão dos papéis sociais, aqui, o termo política será apreendido no âmbito da Linguística, uma vez que é por meio da linguagem que construímos as práticas sociais perpetuadas historicamente. Tais ações determinam a vida social, organizando-a com base na relação de poder entre sujeitos que atuam em um projeto de influência que preconiza o uso da linguagem mediante as relações de força que as instâncias mantêm entre si para construírem o vínculo social.

A par disso, para constituir o corpus, selecionamos discursos políticos de programas eleitorais no HGPE, uma vez que a mídia se tornou um dos principais meios de informação política. Os debates, por exemplo, antes restritos ao âmbito interno dos partidos políticos e ao noticiário impresso, ganharam visibilidade na mídia, inclusive as disputas de prévias dentro dos partidos passaram a ser exploradas pela imprensa. Em decorrência dessa nova configuração, houve o empoderamento não só da instância midiática, para atuar como reguladora da circulação da informação política, mas também de outras instâncias. 
Em uma das eleições presidenciais mais disputadas de toda a história política do Brasil, em 2014, os candidatos Aécio Neves (PSDB) e Dilma Rousseff (PT) protagonizaram programas eleitorais que projetaram, no imaginário social, uma sociedade dividida, ou seja, uma espetacularização da política, incomum num país que se engajava apenas em disputas esportivas, principalmente futebolísticas.

Nesse sentido, o HGPE, como espaço garantido por lei para os partidos apresentarem suas propagandas políticas com o objetivo de governar a pólis, projeta o discurso do enunciador dentro do campo político em que, sabe-se, há algum tempo, trabalham especialistas em marketing e publicidade para tornar as campanhas cada vez mais profissionais e atrativas para o eleitor. Durante o HGPE, o candidato pode dirigir-se aos eleitores de maneira individual ou coletiva; discursar para um grande público; atacar um adversário; veicular mensagens de apoio de seus aliados ou discursos pontuais de seus adversários; utilizar repórteres e atores em cenários ficcionais.

A campanha eleitoral de 2014 teve a mídia como eixo do processo, sobretudo por causa do tempo de propaganda eleitoral na TV e no rádio. No primeiro turno das eleições de 2014 - de 19/08 a 02/10 -, a coligação encabeçada pelo PSDB (Muda Brasil) teve 04min35s ante $11 \mathrm{~min} 24 \mathrm{~s}$ da coligação encabeçada pelo PT (Coligação com a força do povo). No segundo turno - de 10/10 a 24/10 -, cada coligação teve 10min. Os discursos dos dois presidenciáveis que foram ao segundo turno na campanha eleitoral de 2014 intensificaram a polarização histórica entre PT e PSDB devido ao acirramento de posicionamentos, sobretudo em função dos desdobramentos da operação Lava Jato.

Pelo que antecede, podemos afirmar que as campanhas políticas majoritárias são midiatizadas não só por meio do HGPE, mas 
também por pesquisas de opinião, divulgação de agendas, atividades da práxis política que buscam a visibilidade pública dos candidatos. O processo de midiatização ocorre quando o discurso é veiculado pela mídia. $\mathrm{Na}$ disputa pela visibilidade, as campanhas políticas precisam ser atrativas, os discursos, de fácil assimilação, e os candidatos, verdadeiras personagens capazes de "conquistar" o eleitorado. As técnicas da publicidade de mercado são próprias de equipes de marketing político que buscam fazer de seus políticos produtos a serem "consumidos". Face ao exposto, entendemos que o termo "propaganda político-eleitoral" abarca as ações discursivas impressas no HGPE.

A propaganda político-eleitoral é um discurso político e, portanto, de acordo com Charaudeau (2008), é fabricado em sistemas de pensamento, nos atos de comunicação entre atores da cena política e em lugares onde se produz o comentário, em princípio, alheio ao campo da ação política. Na perspectiva do autor, um discurso pode ser considerado político mais pelas condições da situação de comunicação e menos pelo conteúdo, ou seja, o discurso político não se restringe aos governantes, aos candidatos ou aos estudiosos da política; ele se caracteriza político em função da interação e das identidades que dele participam.

Nesse sentido, a mídia pode ser produtora ou propagadora de discursos políticos. Produtora quando desenvolve programas que tratam de temas de relevância social e que pretendem provocar a tomada de decisão de órgãos públicos, por meio da sensibilização do público (tele)espectador. Propagadora quando veicula o discurso político por força de determinação legal - é o caso do HGPE -, ou por meio de fomento - é o caso dos debates entre candidatos políticos. De acordo com Charaudeau (2008), a mídia funciona como um enunciador da informação. Em outras palavras, ela realiza um processo de significação que contempla a construção do 
discurso nas suas diversas configurações - quer verbais, quer não verbais.

No caso concreto desta pesquisa, no gênero de discurso "propaganda político-eleitoral midiatizada”, a instância política apropria-se do espaço da instância midiática para propagar a figura política que pretende ser alçada ao poder político. Para tanto, a instância política escolhe determinados conceitos, imagens e gestos com os quais elabora um processo enunciativo que permite a comunicação com e para a sociedade, num processo de imbricação entre mídia e política.

\section{Categorias de análise: cenografia, ethos discursivo e carisma}

O discurso depende da cena de enunciação para ser de fato enunciado. A cena, segundo Maingueneau (2008a) associa três tipos, a englobante, a genérica e a cenografia, que não são percebidos hierarquicamente, mas a partir do ponto de vista metodológico que o analista assume. A cena englobante equivale ao campo discursivo. Um panfleto entregue na rua, por exemplo, pode ser reconhecido pelo co-enunciador como político, que se une ao gênero de discurso propaganda político-eleitoral, e faz emergir cenografias que se diferem de um discurso para o outro.

A cenografia é caracterizada e construída pelos elementos que compõem a cena de enunciação - textuais e gráficos, por exemplo. Desse modo, a cenografia é uma encenação que, mesmo caracterizada em espaços e gêneros distintos, apropria-se das condições necessárias para se validar. Daí a possibilidade de um político, por exemplo, dirigir-se aos seus eleitores como pai que adverte ou instrui seus filhos. 
Na cenografia, portanto, "papéis" dos sujeitos da enunciação (enunciador - co-enunciador) são projetados, já que o falante, ao mesmo tempo em que projeta um papel discursivo, implica uma relação não só com o papel discursivo do Outro, mas também com as condições espaciotemporais das quais o discurso emerge. É na cenografia que se revelam o ethos discursivo e o carisma.

Pelo que antecede, podemos afirmar que um discurso, muitas vezes, apresenta-se inserido apenas em duas cenas: a englobante e a genérica, dada a necessidade de o discurso ter o campo discursivo e o gênero de discurso definidos. Por exemplo, ao receber um panfleto na rua, o co-enunciador precisa identificar o campo a que pertence tal panfleto, político, religioso etc., a fim de que se enquadre na situação comunicativa adequada (eleitor, cliente potencial de uma empresa etc.) e, por fim, o gênero de discurso precisa ser identificado, uma vez que ele enquadra os papéis dos participantes projetados na cenografia.

Entretanto, esse enquadramento não se dá de forma automática, uma vez que, por meio da cenografia, facetas do enunciador são admitidas no discurso, pois, de acordo com Maingueneau (2008a), de um lado, o discurso impõe sua cenografia de algum modo desde o início, mas, de outro lado, é por intermédio de sua própria enunciação que ele poderá legitimar a cenografia que ele impõe. A cenografia é, concomitantemente, origem e produto do discurso, uma vez que pode ser uma cena típica, já validada, ou se servir de outra para que o co-enunciador legitime o discurso como sendo próprio de tal cenografia e não de outra.

Assim, uma cenografia pode instaurar outras cenas que não as tipicamente validadas para determinados gêneros. Por exemplo, em um pronunciamento aos eleitores, o enunciador, que emerge no discurso de um candidato a presidente, pode estar projetado na cenografia 'conselho de pai' e seus eleitores podem aderir ao 
discurso como filhos. Nesse caso, as cenas englobante e genérica são preteridas e é na cenografia que os coenunciadores interagem efetivamente. A cenografia revela os posicionamentos dos coenunciadores e os efeitos de sentido que concorrem na enunciação, logo, não são os sujeitos empíricos que interagem, mas enunciador e co-enunciador que assumem papéis produzidos na cenografia conselho de pai.

Portanto, o enunciador do discurso político-eleitoral precisa construir para si uma dupla identidade discursiva; uma relacionada ao conceito político e outra que corresponda à prática política: enquanto a primeira refere-se ao posicionamento ideológico do político em relação à vida em sociedade, a segunda insere-o em determinada posição no processo comunicativo da gestão do poder. Decorre do que antecede que, de acordo com Charaudeau (2008), o candidato político recorre à persuasão e à sedução de forma a atrair seu eleitor por meio de características demonstradas pelos seguintes interesses pessoais:

Construir uma imagem de si, um ethos, destinada a assegurar sua credibilidade e oferecer ao público um espetho de identificação; Escolher os modos de interpelação do público que lhe permita se reconhecer dentro de certa identidade cidadã; Saber desqualificar o adversário, pois é necessário se mostrar melhor que o concorrente; Saber exaltar os valores descritos como idealidade social de um bem comum (CHARAUDEAU, 2008, p. 4).

Nessa perspectiva, Charaudeau (2008) assevera que o ethos discursivo está associado a um "cruzamento de olhares", uma troca de olhares entre os coenunciadores - olhar do que fala sobre a forma como acha que é percebido pelo seu público e o olhar do que 
escuta sobre aquele que fala. Essas representações construídas pelo público não se dão exclusivamente no ato da enunciação, pois o discurso, embora constitua um sujeito discursivo, reflete a imagem do enunciador a partir de outros elementos, como vestes, gestos etc. Por isso, o enunciador político pode apresentar um ethos discursivo que é incorporado ao discurso.

A seu modo, Maingueneau (2008b) relaciona ethos à cena de enunciação, ou seja, a noção de ethos permite um estudo mais geral da adesão dos sujeitos a determinados posicionamentos. Para Maingueneau, não existe um ethos preestabelecido, mas, sim, um ethos construído no âmbito da atividade discursiva.

Dessa forma, na perspectiva da $\mathrm{AD}$, o ethos discursivo é um conjunto de características que sempre são relacionadas ao sujeito que revela o próprio modo como se enuncia. Assim, o ethos discursivo trata não do que o sujeito diz a seu respeito, mas do caráter da personalidade que revela esse modo de o sujeito se exprimir. Ele está relacionado com aquilo que o sujeito exprime, expressa, ou seja, marcas de linguagem e aspectos psicológicos que ajudam a entender esse sujeito. Propomos, então, que, na cenografia, há a projeção do ethos discursivo do enunciador, mas não só. Há, também, um traço identitário desse ethos, denominado carisma.

Da busca em alguns dicionários de Língua Portuguesa, pudemos depreender, de um lado, o termo carisma, em sentido lato, como uma habilidade inata de um indivíduo que o torna apto a causar admiração, encantar, persuadir, atrair ou seduzir outro ou um grupo de indivíduos, por meio de uma maneira peculiar de ser e agir. A ideia de que o carisma seja inato não é consenso entre os dicionaristas, visto que alguns argumentam que, como qualquer habilidade, o carisma pode ser aprendido. Em sentido etimológico, por outro lado, o termo carisma vem do grego khárisma, significando graça ou favor, ou seja, um dom gratuito de Deus. 
Ao trazer para o discurso político, um dos discursos mais dominantes do mundo atual, as categorias ethos discursivo e carisma, queremos mobilizar dispositivos teórico-metodológicos de diferentes ciências humanas e sociais, pois o enunciador desse discurso materializa em si e em seu discurso as relações entre as condições sócio-históricas de produção, a linguagem e os posicionamentos. A associação dessas relações autoriza o enunciador a articular, tal como no corpus que selecionamos, sua imagem pessoal com seu conhecimento de política.

De modo geral, o enunciador, em discursos político-eleitorais, procura manifestar, na organização discursiva, não somente o seu conhecimento de política, mas também uma imagem de poder a partir de valores simbólicos que lhes garantem êxito nas eleições. Nesse sentido, é possível apreender cada discurso político, principalmente o midiatizado, como um espaço discursivo que ganha novos efeitos de verdade quando o enunciador utiliza recursos linguageiros e estratégias de marketing político para construir uma imagem carismática de si, posicionando-se, por conseguinte, com poder e autoridade diante dos cidadãos.

Nesse sentido, nosso interesse por relacionar ethos discursivo e carisma corresponde a uma saída teórico-metodológica para a questão da construção da imagem e da comunicação política, especialmente em se tratando da aplicação dessas categorias em discursos proferidos em segundo turno de campanhas para presidente do Brasil. O que buscamos no discurso político-eleitoral é confirmar como o presidenciável se inscreve em seu discurso. A par disso, discutiremos a noção de carisma com o propósito de tomá-la como uma categoria da $\mathrm{AD}$.

A consequência do uso desse conceito de carisma, ainda hoje, permanece presente nos estudos de práticas religiosas, na medida em que carisma se ancora na transcendência, na graça divina, 
dando ao sujeito carismático poder em vida e após a morte sobre aqueles que o reconhecem como salvador da humanidade. Nesse sentido, podemos afirmar que, em contextos de relações de domínio e poder, tanto religiosos quanto políticos, o carisma causa admiração.

Considerando as várias abordagens da noção de carisma e de sua aplicação em análise de práticas e crenças religiosas, recorremos a essa categoria para o estudo do discurso político-eleitoral, porque, para nós, o sujeito político pode ser um indivíduo admirável, poderoso, fascinante e sedutor, se observado do ponto de vista da instância política. Além disso, qualquer sujeito que utiliza o espaço público para se manifestar como político pode ser reconhecido como portador de carisma, se assim for legitimado por outro indivíduo ou por um grupo. O carisma é, portanto, um traço fundamental da imagem de poder do político enquanto líder, ou seja, um modo de subjetividade, uma forma de manifestação de sua interioridade, um comportamento do enunciador, sua relação com ele mesmo e com o Outro.

É a partir dessa evidência que podemos relacionar o ethos discursivo ao carisma que se manifesta em meio a um acordo de permuta entre os coenunciadores do contrato de comunicação. $\mathrm{Na}$ perspectiva de Charaudeau, o carisma resulta da interação entre a imagem do enunciador e a forma como sua expressividade ecoa no seu co-enunciador, atraindo-o de modo a levá-lo a identificar-se com o enunciador como uma necessidade essencial. Assim, a categoria carisma não só se define como um meio de identificação, mas também como um ideal a ser absolutizado.

O ethos discursivo, por sua vez, é sempre um movimento em construção, e o carisma participa desse fenômeno. É a questão do ethos discursivo levado ao extremo, pois o carisma não se funda na legitimidade; é uma vantagem que se sobrepõe à legitimidade, na 
medida em que um sujeito pode ter uma legitimidade institucional, mas não ter carisma. Ter carisma é mais que conseguir credibilidade e aceitação do público.

Desse modo, o carisma político caracteriza-se pelo poder, pela capacidade de dominação do líder político. Seu discurso é constitutivamente marcado pela projeção do ethos discursivo e pela sedução emanada do carisma, que instauram, no funcionamento discursivo, um processo de fascínio garantidor da eficácia do político. Nesse sentido, o enunciador busca estabilizar uma auto-imagem, um ethos discursivo de credibilidade, para tanto, incita o público a identificá-lo, reconhecer nele uma identidade cívica particular capaz de desqualificar o adversário, destacando o enunciador como melhor.

O processo de enunciação, portanto, ocorre numa imbricação do que é dito com o que se projeta ao dizer, ou seja, o enunciador, quando profere o discurso, busca a adesão do co-enunciador por meio de recursos discursivos que acabam por dissociar o sujeito portador do rosto, da voz e do corpo, daquele sujeito que se diz, o enunciador.

O enunciador, nas palavras de Nascimento (2013), é constituído na relação da linguagem com o social, em outras palavras, o enunciador joga com máscaras, conforme sua historicidade e a de seu co-enunciador, a fim de negociar os efeitos de sentido de seu discurso, visando a ter constituído o ethos discursivo de sujeito carismático.

Assim, o mundo comum da política reveste-se de sacralidade, o que permite a criação de "profetas" (candidatos) 'cheios' de carisma e, à maneira religiosa, a constituição de um grupo de "discípulos" (eleitores), pois o carisma, manifestado no discurso de uma campanha político-eleitoral, pode arrebatar os corações e, portan- 
to, os votos de eleitores, na medida em que ocorre uma apropriação, pelo enunciador, de instituições, de discursos e de imagens de outrem que avalizam o dito.

\section{Rostos e máscaras no discurso político: efeitos de verdade}

É a partir da exterioridade e da interioridade do posicionamento do enunciador que podemos relacionar o ethos discursivo ao carisma, que se manifesta em meio a um acordo de permuta entre os coenunciadores no contrato de comunicação. A par disso, propomos, então, as noções de carisma subjetivo e carisma objetivo.

O carisma subjetivo (Esquema 2) manifesta-se exclusivamente no detentor da voz, na figura humana, no sujeito empírico dono do rosto, trata-se, portanto, do carisma para além da dominação, ou seja, uma qualidade performativa em que práticas corporais e sensoriais são fundamentais para o estabelecimento da autoridade e da legitimidade do candidato político. 
MASCARAS

Carisma objetivo

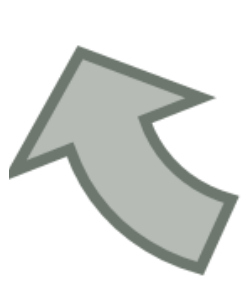

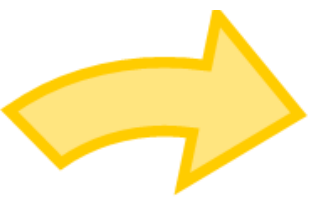

CONDIÇŌES

Carisma objetivo

SUJEITO

\section{CARISMÁTICO}

ROSTO

Carisma subjetivo

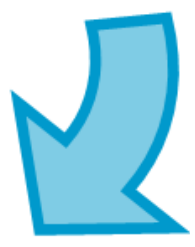

Esquema 2. Carisma Subjetivo - circunstância de imagem projeção do Sujeito Carismático (SOUZA, 2018, p. 117)

Quanto ao segundo, o carisma objetivo (Esquema 3), emerge de condições distintas, ou seja, de condições externas ao sujeito empírico, que se internalizam no discurso e que projetam um enunciador com ethos discursivo de candidato carismático.

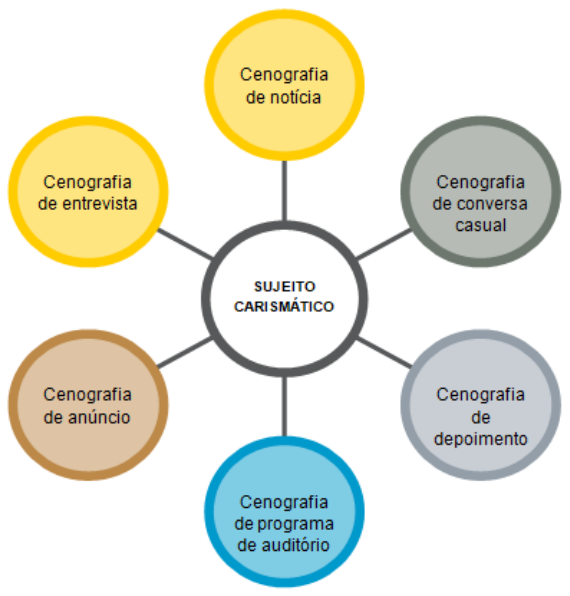

Esquema 3. Carisma Objetivo - circunstância de cena projeção do Sujeito Carismático (SOUZA, 2018, p. 119) 
Por um lado, o carisma subjetivo é associado às características de transcendência e de atração, que podem ser apreendidas pelo modo de falar e gesticular do enunciador, por exemplo. Desse modo, o carisma subjetivo está, de certa maneira, ligado ao corpo de quem enuncia e se manifesta diante de duas forças opostas: o poder e o povo. No cruzamento dessas forças, o carisma subjetivo torna-se fator crucial para a atuação do enunciador, pois ajuda na promoção de discursos sedutores, gerando a necessidade de o enunciador ter de oscilar entre a lógica simbólica e a lógica pragmática para atingir seus objetivos de adesão.

A circunstância de imagem toma o rosto como força simbólica na relação com máscaras e condições que circunscrevem o projeto de dizer do enunciador e o colocam em cena, ou seja, tal circunstância projeta ethé discursivos em certas condições sócio-históricas de produção (lugar e tempo) que visam à validação do discurso por parte do co-enunciador. Este, por sua vez, associa a imagem pessoal do enunciador ao seu conhecimento de política e à sua competência linguístico-discursiva, incorporando discursividades que envolvem o verbal e o não verbal.

Esse é o processo discursivo em que ocorrem os programas político-eleitorais no HGPE, lugar em que se busca construir a imagem de candidato carismático por meio de cenografias e ethé discursivos que fazem parte do propósito do enunciador de obter legitimação pelo co-enunciador que, enquanto membro de uma comunidade discursiva, tem, na memória discursiva, elementos que podem, por um lado, validar e, por outro, invalidar a figura de poder projetada na tela do televisor.

Consideramos que o carisma do sujeito é projetado não só por meio de máscaras, condições de produção e cenografias, mas também pelo rosto do candidato, e se constitui como traço do ethos 
discursivo do enunciador. No HGPE, há uma encenação proposta por profissionais de marketing que, em um processo de midiatização dos discursos políticos, envolve o co-enunciador em circunstâncias que visam à validação não só da cena, por meio de cenografias variadas, cujos scripts são reconhecíveis, mas também do rosto e de ethé discursivos que sacralizam o enunciador como mais honesto, mais crível, mais comprometido, mais realizador, mais humano, em outras palavras, a circunstância de imagem busca sacralizar o enunciador como sujeito carismático.

Por outro lado, o carisma objetivo se constitui nas cenografias que circundam a propaganda político-eleitoral midiatizada. Em nossa Tese (SOUZA, 2018), verificamos que a desconstrução da imagem do oponente, por meio de falas de jornalistas, manchetes, pesquisas, diálogos casuais, mostra-se como recurso discursivo, por meio do qual dados externos ao discurso são alocados para a situação de comunicação e objetivam projetar o ethos discursivo do enunciador em confronto com o ethos discursivo projetado do adversário.

\section{Constituição e análise da amostra}

Os programas político-eleitorais do segundo turno da campanha eleitoral de 2014 foram transmitidos pelos canais de televisão aberta entre $13 \mathrm{~h}$ e $13 \mathrm{~h} 20$ / 20h30 e 20h50, do dia 11/10 ao dia 23/10/2014. Ao todo foram quarenta minutos diários de programas que interromperam a transmissão normal dos canais. $\mathrm{Na}$ Tese (SOUZA, 2018), selecionamos de seis programas noturnos do HGPE dez discursos (D) de cada candidato, que perfizeram um total de cento e onze recortes (R). Aqui, apresentamos apenas um discurso de cada candidato. Com propósito metodológico para re- 
alizar as análises, utilizamos recortes dos discursos disponíveis no site Youtube.com. Na tabela, apresentamos o corpus assim: discurso (D), data, recorte (R) e descrição dos efeitos de verdade.

\begin{tabular}{|c|c|c|c|}
\hline Discursos & Data & Recortes & $\begin{array}{l}\text { Descrição dos efeitos de } \\
\text { verdade }\end{array}$ \\
\hline D1: Aécio & \multirow[t]{3}{*}{11 e $16 / 10 / 14$} & \multirow{3}{*}{$\begin{array}{l}\mathrm{R} 1, \mathrm{R} 2, \mathrm{R} 3, \\
\mathrm{R} 4 \text { e R5. }\end{array}$} & \multirow{3}{*}{$\begin{array}{l}\text { O enunciador se posiciona como } \\
\text { representante da instância ad- } \\
\text { versária por meio de cenografias } \\
\text { que relacionam o nome de Aécio } \\
\text { com o Brasil. As circunstâncias } \\
\text { de imagem e de cena projetam } \\
\text { o enunciador como uma espécie } \\
\text { de 'a marca da mudança de que o } \\
\text { Brasil precisa'. }\end{array}$} \\
\hline $1^{\circ}$ Programa & & & \\
\hline $3^{\circ}$ Programa & & & \\
\hline D2: Dilma & \multirow[t]{4}{*}{11 e $14 / 10 / 14$} & \multirow{4}{*}{$\begin{array}{l}\text { R1, R2, R3, } \\
\text { R4, R5, R6 } \\
\text { e R7. }\end{array}$} & \multirow{4}{*}{$\begin{array}{l}\text { O enunciador se posiciona, por } \\
\text { meio de circunstâncias de ima- } \\
\text { gem e de cena, como: liderança } \\
\text { valente na luta pela democracia } \\
\text { em anos de ditadura militar; víti- } \\
\text { ma de perseguição política; pre- } \\
\text { sidente séria, experiente, querida } \\
\text { pelo povo brasileiro e apta para } \\
\text { continuar mandatária do Brasil. }\end{array}$} \\
\hline $1^{\circ}$ Programa & & & \\
\hline $2^{\circ}$ Programa & & & \\
\hline $3^{\circ}$ Programa & & & \\
\hline
\end{tabular}

Tabela 1. Descrição da amostra - Discursos de Aécio (D1) e de Dilma Rousseff (D2)

\section{D1 - AÉCIO - $1^{\circ}$ e $3^{\circ}$ PROGRAMAS - 11 e $16 / 10 / 2014$}

O D1, pela cenografia, instaura o enunciador como representante da instância adversária, por meio de cenografias que relacionam o nome de Aécio com o Brasil. As circunstâncias de imagem e de cena projetam o enunciador como uma espécie de 'a marca da mudança de que o Brasil precisa'. 


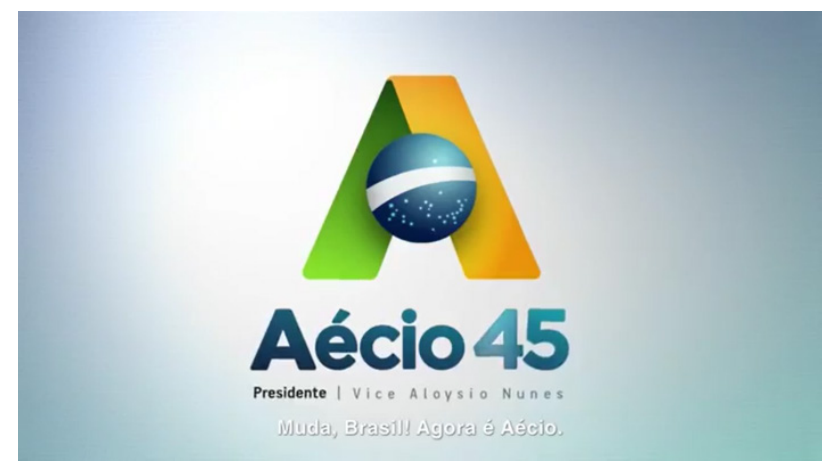

R1

Aécio - $1^{\circ}$ Programa - 00:09:58

Para constituição da cenografia do discurso da instância adversária, o enunciador utiliza a letra $A$ em maiúsculo [R1] com as cores verde, branco, amarelo e azul, que representam as cores da bandeira do Brasil. Está centralizado na cenografia, logo abaixo da letra $\mathrm{A}$, o nome Aécio e o número 45, que representam a instância adversária e o posicionamento que assume frente à instância política ao acionar, na memória discursiva, o número 45. Logo abaixo do nome Aécio, há o nome do vice e a marca do posicionamento do enunciador que, ao proferir o enunciado "Muda Brasil, agora é Aécio", assume uma formação discursiva que o define.

O cargo de presidente e a indicação do vice Aloysio Nunes são dados que buscam recuperar, na memória discursiva do enunciador, conhecimentos que situam o enunciador como o Presidente de que o Brasil precisa: único brasileiro que pode mudar o país. Apesar de haver o número da sigla, não há outra referência que evidencie o partido político (PSDB) do candidato. Trata-se, portanto, de uma negociação de efeitos de sentido entre enunciador e co-enunciador, uma vez que o primeiro diz, sem dizer, que está filiado a um partido político por imposição de lei e o segundo é conduzido a confiar no enunciador e não em seu partido. 


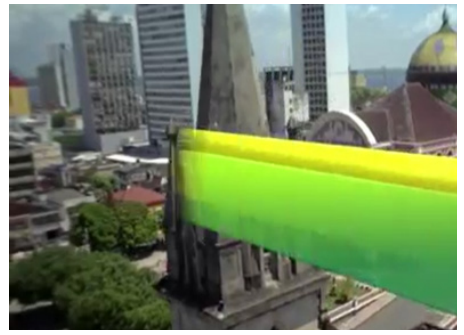

R2

Aécio - $3^{\circ}$ Programa - 00:00:01

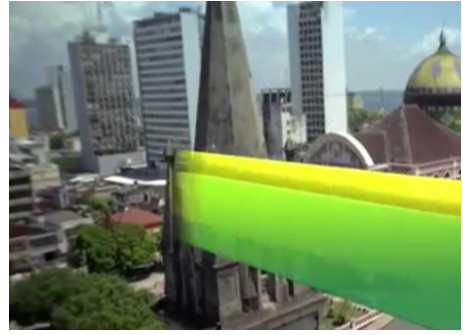

R3

Dadas às condições sócio-históricas em que o discurso está inscrito, campanha eleitoral pós-manifestações em todo o país, uma das estratégias do marketing político foi omitir informações que vinculassem explicitamente o candidato a um partido político, uma vez que a maioria das agremiações estava sob investigação policial.

A cenografia nos R2 e R3, sem qualquer alusão ao PSDB, é constituída com base em linhas com as cores verde e amarela [R2 e R3] que "percorrem" diferentes regiões do Brasil, numa tentativa de mostrar, por meio de recursos gráficos, que as ideias do enunciador estão contagiando todo o país. A circunstância de cena projeta o enunciador como uma espécie de 'a marca da mudança de que o Brasil precisa, em um locus que oferece ao enunciador competências ética e situacional que fazem com que o discurso seja considerado de acordo com diferentes efeitos de verdade, visando a marcar a identidade e/ou a contrariedade do enunciador no ato enunciativo. 


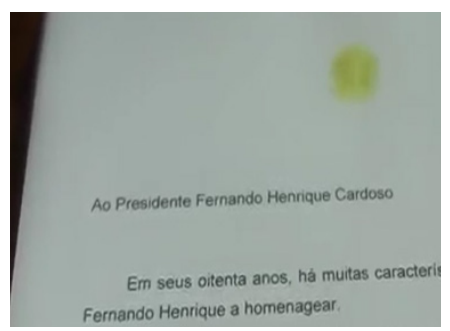

$\mathrm{R} 4$

Aécio - $1^{\circ}$ Programa - 00:00:09

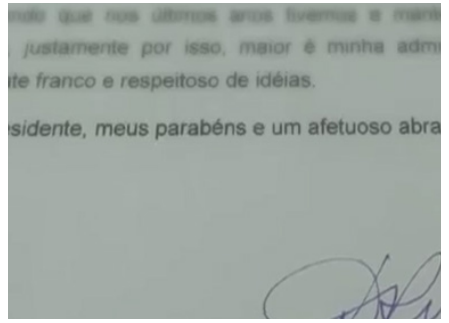

R5

Aécio - $1^{\circ}$ Programa - 00:01:10

Para constituição da cenografia, o enunciador profere um enunciado o qual etiqueta como 'carta ao ex-presidente FHC assinada pela presidente do Brasil' [R4], encaminhada pela presidente Dilma Rousseff na ocasião do aniversário de FHC. Enquanto narra, o enunciador focaliza o nome de quem assina a carta: Dilma Rousseff, fiadora do discurso do enunciador [R5]. Essa estratégia situa o discurso na Circunstância de cena, em que o enunciador constrói uma cenografia de declaração pública positiva feita pela instância política sobre as qualidades de um correligionário do PSDB e, depois de narrar o conteúdo da declaração, questiona: quem fala a verdade? A Dilma que ataca para ganhar votos ou a Dilma que escreve e assina embaixo? Tal atitude projeta, ao mesmo tempo, um ethos discursivo da instância adversária, de vítima de ataques injustos, e um ethos discursivo da instância política, de desesperada para ganhar as eleições, faces que objetivam influenciar o posicionamento do co-enunciador.

Ao apresentar um documento com a etiqueta de 'carta assinada pela presidente do Brasil', o enunciador quer conferir um efeito de verdade, afinal, a assinatura da proponente indica não só seu conhecimento formal do conteúdo, mas também expressa sua vontade de reconhecê-lo. Nesse sentido, a cenografia em cur- 
so 'declaração pública positiva feita pela instância política sobre as qualidades de um correligionário do PSDB’ busca estabilizar o gênero de discurso 'declaração de reconhecimento da qualidade dos governos tucanos pela presidente da República'. Com isso, o efeito de sentido negociado é, se a própria presidente sabe quão eficientes foram os governos do PSDB, logo, a instância cidadã também o saberá. A cenografia projeta, desse modo, os papéis do enunciador e do co-enunciador, quais sejam, propagador de verdades e legitimador de verdades.

Vemos, portanto, que a cenografia é uma encenação que, mesmo caracterizada em espaços e gêneros distintos, promove a força do ethos discursivo e do carisma e constrói condições necessárias para ser legitimada. Daí a possibilidade de o enunciador, por meio de jogos de máscaras e de cenografias, poder dirigir-se ao co-enunciador como aquele que possui provas da falta de coerência em atitudes da instância política.

\section{D2: DILMA - 1', $2^{\circ}$ e $3^{\circ}$ PROGRAMAS - 11, 14 e $16 / 10 / 2014$}

O D2 posiciona o enunciador, por meio de circunstâncias de imagem e de cena, como liderança valente na luta pela democracia em anos de ditadura militar; vítima de perseguição política; presidente séria, experiente, querida pelo povo brasileiro e pronta para continuar mandatária do Brasil. 


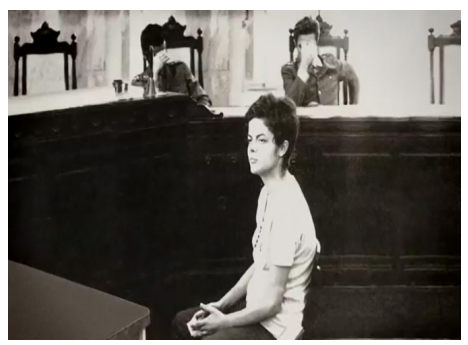

R1

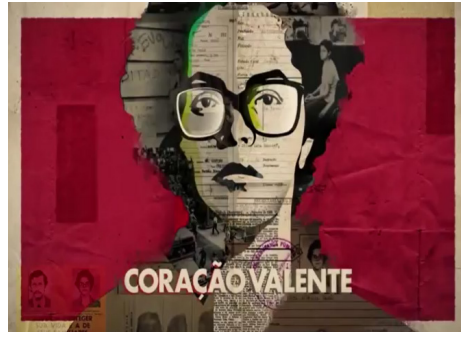

R2

Dilma - $1^{\circ}$ Programa - 00:08:59

Dilma - $1^{\circ}$ Programa - 00:09:59

Nos R1 e R2, o enunciador, para constituir a cenografia, lança mão de um fiador discursivo que avaliza sua trajetória política: sua própria luta contra a ditadura militar. Essa estratégia discursiva busca mobilizar, na memória discursiva do co-enunciador, dados que legitimem uma combatente do regime militar como sujeito capaz de combater os malfeitores e sujeito valente para tocar obras e projetos importantes para o Brasil. Por meio da cenografia de biografia pessoal e profissional, da relação do histórico de luta com as realizações do enunciador como Presidente da República, o ethos discursivo projetado é o de candidata experiente e preparada para ser, novamente, presidente do Brasil. Tudo se dá em um jogo de máscaras, em que o enunciador busca atribuir a si o poder ser para poder fazer. Em outras palavras, os efeitos de sentido negociados buscam estabilizar o seguinte: se o enunciador venceu os ditames de um regime autoritário e conseguiu ser presidente da República, apesar de sua condição estereotipada, continua habilitado para continuar sendo mandatário do Brasil.

Apropriando-se do poder da mídia, o enunciador é mostrado por meio de cenografias que registram sua atuação política desde a tenra idade. Essa atitude está associada à Circunstância de cena. A cenografia de biografia pessoal e profissional pretende não só 
projetar o ethos discursivo do enunciador de mulher guerreira e valente, mas também estabelecer o papel social do co-enunciador, admirador de políticos que venceram regimes autoritários e que são defensores da democracia.

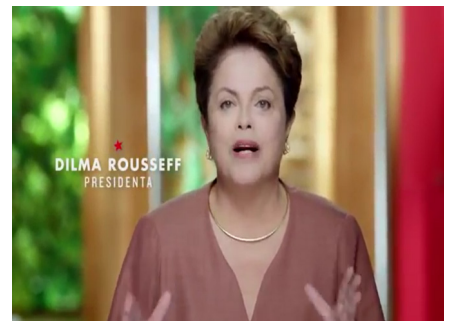

R3

Dilma - 2o Programa - 00:00:43

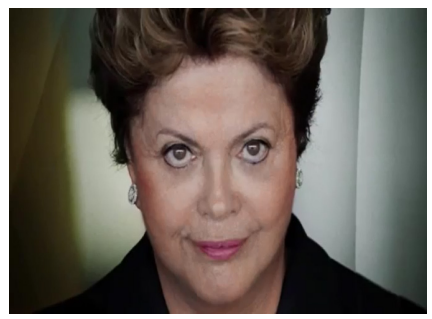

R5

Dilma - 3º Programa - 00:07:27

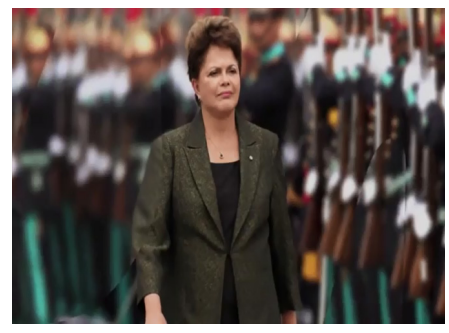

R4

Dilma - 3o Programa - 00:07:26

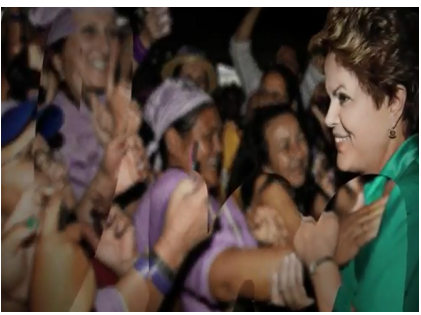

R6

Dilma - 3o Programa - 00:07:38

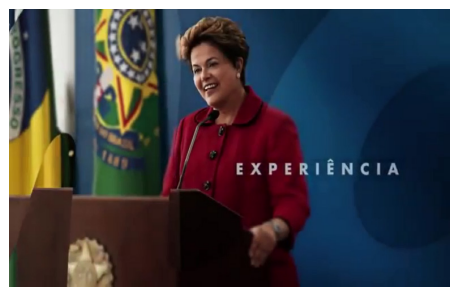

R7

Dilma - 3º Programa - 00:07:45 
Já nos R3-R7, para constituição da cenografia, o enunciador distancia-se do arquétipo comum aos candidatos em época de eleições, ou seja, não apresenta familiares felizes que demonstram apoio à sua campanha. Ao contrário, apresenta-se como eixo de sua própria trajetória política. Nessa perspectiva, o enunciador negocia efeitos de sentido ao mostrar que, outrora, estava em xeque diante de militares [R1], mas, atualmente, figura, paradoxalmente, como líder das forças armadas [R4]. Isso ocorre por meio da interdiscursividade entre os discursos institucional e de luta política. $\mathrm{O}$ objetivo é seduzir o co-enunciador para que ele adira ao discurso.

Com efeito, o fato de o discurso ser midiatizado faz com que estratégias discursivas do campo político, quais sejam, utilização de recursos midiáticos que projetam imagens diversas do enunciador no imaginário social; estímulo da competência discursiva do co-enunciador, revelem as formações discursivas do enunciador, a fim de que seu ethos discursivo seja validado como melhor. Para tanto, nos R3-R7, o enunciador apresenta traços do sujeito, corpo, rosto e gestos, que projetam uma identidade social: uma mulher guerreira, valente.

Assim, os efeitos de sentido negociados são engendrados em diferentes cenografias - fotografias [R4, R5, R6, R7], cumprimentos [R6], depoimentos [R1], desfiles [R4], condições externas que são internalizadas no discurso e projetam uma qualidade extracoditiana do enunciador - que projetam o ethos discursivo e um carisma objetivo do enunciador, na medida em que o realçam como superior a seus adversários políticos.

Isso indica que tais cenografias, aliadas ao rosto da mulher, e aos ethé discursivos de estudante engajada, valente, perseguida pelos militares [R1, R2], primeira mulher eleita Presidente do Brasil [R3], política séria [R5], experiente [R7] e amada pelo povo [R6], imprimem competência e habilidade ao enunciador e constroem 
um carisma subjetivo, na medida em que busca credenciar o enunciador, no imaginário social, como candidato político mais bem preparado para continuar com as políticas públicas de que o Brasil precisa.

Tais estratégias discursivas são realizadas em discursos nos quais o verbal e o não verbal colaboram para a construção do sujeito político mais carismático, capaz de arrebatar corações e conquistar os votos necessários para sua vitória.

\section{Considerações finais}

Com esta pesquisa, pudemos examinar os efeitos de verdade em discursos proferidos por Aécio Neves e Dilma Rousseff, no HGPE (Horário Gratuito de Propaganda Eleitoral), na ocasião do segundo escrutínio das eleições brasileiras de 2014. No discurso político-eleitoral, são projetados efeitos de verdade na cena política, de modo que o enunciado, aos seus eleitores, busca ascender-se como homem do povo, "enviado de Deus", experiente, tecnocrata etc. Essas possibilidades permitem reconstruir cenografias do dado discurso e desvelar o ethos discursivo, pois política é, na verdade, lugar da linguagem e da negociação de efeitos de sentido, em que atos de linguagem permitem a busca pela adesão do co-enunciador. Dessa forma, o ethos discursivo de sujeito político carismático é manifestado na medida em que esse carisma influencia o co-enunciador para que ele creia, ou seja, dê credibilidade ao discurso.

Nesse sentido, no HGPE, o enunciador apresenta um carisma produzido em cenografias próprias da mídia que promovem um projeto de dizer e, por conseguinte, instauram um processo de sedução em que o co-enunciador é levado a legitimar um ethos dis- 
cursivo do enunciador que, enquanto ser no/do mundo, direciona sua imagem de carismático para o outro e, assim, busca, nos funcionamentos discursivo e corporal, manifestar maneiras discursivas de ser e de falar que projetem efeitos de verdade e conquistem a adesão do Outro.

Assim, o sujeito político carismático emerge da imbricação da circunstância de imagem com a circunstância de cena, ou seja, das projeções dos carismas subjetivo e objetivo, da concorrência entre instâncias enunciativas (política, adversária, religiosa, jurídica, econômica e empresarial) que, na cena político-midiática, buscam estabilizar o discurso em cenografias validadas pelo co-enunciador para sacralizar o enunciador e fazer com que corações sejam tocados e votos sejam garantidos nas eleições. Afinal, no jogo político, em que ganha quem mais seduzir o Outro, paixões afloram e norteiam os debates.

Nas palavras de Charaudeau (2008, p. 12), na cena política, o enunciador lida com 'máscaras', ou seja, toda palavra pronunciada no campo político deve ser tomada ao mesmo tempo pelo que ela diz e não diz. Jamais deve ser tomada ao pé da letra, numa transparência ingênua [...]. Desse modo, os discursos aqui analisados, potencializam os jogos de aparência e projetam efeitos de verdade, pois, ao enunciador, ancorado por instâncias, conglomerados empresariais, industriais, midiáticos, religiosos etc., oferece-se, por meio de rostos e máscaras, nas cenografias constituídas, a possibilidade de se mostrar carismático, honesto e bom gestor da coisa pública. 


\section{Referências}

BOBBIO, Norberto. Dicionário de política. Tradução: Carmen C, V. et alii.; coord. trad. João Ferreira; rev. geral João Ferreira e Luis Guerreiro Pinto Cacais. - Brasília: Universidade de Brasília, 1998.

CHARAUDEAU, Patrick \& MAINGUENEAU, Dominique. Dicionário de análise do discurso. São Paulo: Contexto, 2016.

CHARAUDEAU, Patrick. Charisme quand tu nous tiens - Les paradoxes du charisme en politique. Université Paris XIII - CNRS-LCP. Paris, le 20 avril 2012.

. Discurso das mídias. São Paulo: Contexto, 2006.

. Discurso Político. São Paulo: Contexto, 2008.

MAINGUENEAU, Dominique. Cenas da enunciação. Tradução Maria Cecília Pérez de Souza-e-Silva; Nélson P. da Costa e Sírio Possenti. Curitiba: Criar, 2008a.

. A propósito do ethos. Trad. Luciana Salgado. In: MOTTA, Ana Raquel \& SALGADO, Luciana (org). Ethos discursivo. São Paulo: Contexto, 2008b.

. A Análise do Discurso e suas Fronteiras. Tradução Matraga. Rio de Janeiro: UERJ, 2007.

NASCIMENTO, Jarbas Vargas. Espaços da textualidade e da discursividade no ensino de leitura e escrita em Língua Portuguesa. São Paulo: Terracota, 2013.

NEVES, Aécio. D1 - 11/10/2014. Horário Gratuito de Propaganda Eleitoral. Disponível em: https://www.youtube.com/watch?v=Ma8N1ILu-o4. Acesso: 22/09/2015, $20 \mathrm{~h} 32$.

ROUSSEFF, Dilma. D2: DILMA 14/10/2014. Horário Gratuito de Propaganda Eleitoral. Disponível em: https://www.youtube.com/ watch?v=2CqaYCo5_yE. Acesso: 22/09/2015, $20 \mathrm{~h} 59$.

SOUZA, Rudney. A práxis política em cena no Brasil: ethos, caris- 
ma e poder no discurso eleitoral midiatizado. Tese de Doutorado. Pontifícia Universidade Católica. São Paulo, 2018.

- O ethos da 'nova voz' na casa das nações. In: SALEM, K. (Org.) Estudos em Linguagem e Educação. (CAELE - Coletânea Acadêmica de Estudos em Letras e Educação). São Paulo: Fiuza, 2012, p. 127-135.

. Discurso Presidencial: a imagem da mulher em cena. Dissertação de Mestrado. PUC-SP, 2013. 